\title{
El Quijote, con la arbitraria corrección de al momento por al jumento
}

\author{
Juan Antonio Frago \\ Universidad de Zaragoza
}

\section{VARIANTES HISTÓRICAS Y CRITERIO FILOLÓGICO}

\begin{abstract}
Al Quijote se ha dedicado un abrumador número de estudios literarios y de toda clase de erudición, que muy lejos dejan a los estudios lingüísticos que esta obra ha merecido, cuando los cervantistas tanto blasonan, en alguna que otra ocasión con vaguedades y pretenciosas máximas, de su extraordinaria importancia para la historia del español, como sinónimo o paradigma se ha llegado a identificar la lengua de Cervantes con la lengua española, siendo también que el mismo autor enaltece su valor lingüístico en el extraordinario dominio del vocabulario que en su composición hizo gala, en sus variados y logrados juegos semánticos, incluso en detalles como la hilarante réplica de Sancho a la dueña Dolorida (II, 38, p. 1027), donde, mejor que en cualquier tratado gramatical, con escuetos, precisos, y preciosos, trazos se dibuja la certera idea de Cervantes sobre la actualidad y el estilo del sufijo -ísimo en la época; por no hablar de sus consideraciones sobre "el lenguaje puro, el propio, el elegante y claro", y su adquisición por el hablante, aun por el nacido en la aldea. Si no fuera también por la profética proyección que a su genial novela concede en la Dedicatoria al Conde de Lemos de la segunda parte, con la oportuna invención de que "el grande emperador de la China" le escribe, "pidiéndome o por mejor decir suplicándome se le enviase, porque
\end{abstract}


quería fundar un colegio donde se leyese la lengua castellana y quería que el libro que se leyese fuese el de la historia de don Quijote" (II, 678-679)1.

Ahora bien, en el análisis lingüístico del Quijote hay que huir de groseros errores como los de tomar escrebir y recebir por casos de vacilación vocalica en relación con escribir y recibir, tratándose de meros resultados de una antigua disimilación $i \ldots i>e \ldots i$, dominantes en el castellano medieval, como disimilatorio por partida doble, vocálica y consonántica, fue el cambio de vivir a bevir (berceano "de bevir en tal guisa, sabe Dios, non me pago" $)^{2}$, o el de volver en bolver registrado en los autógrafos cervantinos, asimismo en el Quijote y en Covarrubias (1611/1984: 227). Así como el de creer que el cardinal mil en su grafía mill, durante mucho tiempo simple reminiscencia latinizante, refería con su $-l l$ a la palatal /1/, algo que la propia distribución fonemática de nuestra lengua niega, y que Nebrija no contemplaba en sus diccionarios, reprochando el humanista andaluz "el error de los que escriven... mill, con doblada l" (1492/1981: 131-132), la única que Cervantes emplea en sus autógrafos $(2,3,5,9,10)$, poniendo en el (4) nueve veces mil y seis mill, grafía constante en la parte de este documento debida a escribano público, exclusiva asimismo en el amanuense concejil del séptimo original ${ }^{3}$. Tampoco es aceptable el que sea "interesante la conversión de -ae en -ay, un diptongo más fácilmente reconocible: tray "trae"" (Gil 2015: 118). Efectivamente, "por ver si tray alguno de alguna vacante" se lee en (1), el de más cuidada letra, cancilleresca, dirigido por Cervantes al influyente Antonio de Eraso, "del Consejo de Yndias"; pero se trata de una tercera persona verbal bisílaba, con hiato de la $a$ lexemática y de la $e$ desinencial, en este caso con solución antihiática diptongada de la que hay no pocos testimonios antiguos, así un "trairé en el dicho navío

1 El texto del Quijote se cita por la edición de F. Rico de 2015 y las cuestiones lingüísticas por su volumen complementario (VC), los manuscritos originales de Cervantes por Autógrafos entre paréntesis.

2 Tampoco es cuestión de vacilación vocálica, error en el que no pocos filólogos continúan cayendo, piénsese que se trata de vocales tónicas, el doblete mesmo-mismo, la primera forma de amplísimo dominio en el castellano medieval, ambos términos alternantes en entrada de Covarrubias, con preferencia de Correas por mesmo, aunque con la advertencia de que "algunos mudan la primera sílaba me en mi i dizen mismo, misma", con 222 casos en el Quijote por 177 de mismo (Frago 2015: 158), mientras que el predominio de mesmo es abrumador en sus escritos autógrafos.

3 Claro que el uso de mill no fue solo propio de notarios, curiales y escribanos de cabildo o eclesiásticos, sino de todo el entramado forense y de cultos familiarizados con esta costumbre escrituraria; Cervantes sabía de pleitos y de tratos notariales, y su papel de comisario real en Andalucía lo mantuvo en frecuente contacto con amanuenses municipales. 
todas las mercaderías", de 1550, y tres "sin le pedir por el riesgo ni por el registro ni por la traydura cossa alguna", de $1600^{4}$.

Es frecuente ver cómo se acumulan vacilaciones fonéticas de toda clase, algunas sin serlo, dándose así la impresión de una lengua inestable, nunca lo fue, sin advertir de la ocasionalidad o frecuencia de los ejemplos aducidos y sin fijar con suficiente rigor los límites del vulgarismo y del uso culto en aquella sincronía, o sin contar con la correspondiente precedencia histórica, pues, por ejemplo, en el Quijote aislados registros de adevinar, inquerir y lígitimo, coexistentes con adivinar, inquirir y legítimo, no eran indicios de aldeanismo, presona y presonaje sí, antes en rústicos de Torres Naharro. El criterio númerico ayuda a descubrir la aceptación o el rechazo entre variantes, o la misma atribución del autor, circunstancias concurrentes en ceremonias y cirimonias, esta para la Duquesa propia del habla escuderil, "como vos decís" (II, 32, p. 986), y sus dos testimonios están en intervenciones sanchescas, frente a 22 de ceremonia, uno también en boca de Sancho. Y la complejidad del español clásico en pasaje del narrador también aporta cerimonia (I, 15, p. 173), variante etimológica de ceremonia "muy corriente hasta el siglo XVII" y "la más clásica en latín” (Corominas y Pascual 1980-1991: II, 44), y es aún entrada única, junto a la del sufijado ceremoniático, en Covarrubias, que en su explicación solo emplea cerimonias (1611/1984: 409). No hay aquí, pues, vacilación de timbre vocálico, sí en cirimonia, tampoco en envidia-invidia, puro latinismo el segundo elemento, embidia en Nebrija, en Covarrubias embidia e invidia sin nota diferencial (1611/1984: 505506,740 ), igual que en el Quijote. Ni puede sumarse a las "vacilaciones" vocálicas el doblete monasterio-monesterio, el segundo término casi general hasta el Siglo de Oro, exclusivo en Nebrija, con tres registros cada uno en el Quijote (Fernández Gómez 1962: 683-684), pero un siglo antes en el testamento autógrafo de Juan Coloma se da el predominio de monasterio sobre monesterio (Frago 2018: 241); formas que no se deben a un cambio entre /a/ y /e/, sino a simple diversidad etimológica (Corominas y Pascual 1980-1991: IV, 128).

\footnotetext{
4 Archivo Histórico de Protocolos de Cádiz, notaría 19, legajo 4.338, f. 918v; legajo 4.365, fs. 66v-67v, y un trai se halla en carta de Pascual de Andagoya a Carlos V, de 1.540: BNE, ms. 19.267, f. 11r. En época de Cervantes el antihiatismo, si no era reiterado, no indicaba incultura. En el Quijote solo hay proveedor, mientras el popular con sinéresis provedores exclusivo, con 16 casos en Autógrafos $(5,6,11)$, cuando los escribanos de (7) y (8) solo emplean esta voz con su hiato originario. Y nótese el antihiatismofonosintáctico de haui hecho por hauía hecho en (10), tal vez debido a las condiciones en que anotaba sus requisas.
} 


\section{VARIACIÓN SIN CAOS LINGÜÍSTICO}

El indiscriminado acarreo de datos sobre variación lingüística sin la debida depuración filológica y contextualización histórica inevitablemente lleva a conclusiones desenfocadas. Así, quiriendo es uso sistemático en el Diálogo valdesiano, pero ya de empleo variable en le época de Cervantes, y en el Quijote tiene 2 registros por 11 de queriendo, señal de que esta forma no tardaría en ser exclusiva entre cultos. En cuanto a las alternancias de voces con grupos consonánticos conservados o reducidos (doctor-dotor, maligno-malino, etc.), en Cervantes y en cualquier otro autor de su tiempo no es una cuestión de impulsivas o caprichosas alteraciones cuasi caóticas, sino de una situación de competencia entre la tradición y la innovación, tradición castellana bien representada por Juan del Encina y Juan de Valdés de relajamiento y pérdida del elemento implosivo, con no poca vigencia hoy en hablas populares de todo el mundo hispánico, y la reacción cultista de su mantenimiento. Su autógrafo (1) trae correción, con 3 registros en el Quijote, ninguno de corrección; los originales (4) y (11) tienen 4 setiembre, 3 otubre y 3 octubre, en la novela hay 6 doctrina / 0 dotrina, 20 ignorante / 0 inorante, pero 6 letura/ 0 lectura, 10 acetar / 4 aceptar, con bastante apego a la tradición en este punto, desde luego en mayor grado que el más latinizante Covarrubias. Pero el estilo puede condicionar una mayor presencia del latinismo consonántico, así en las dedicatorias y prólogos del Quijote.

El texto quijotesco naturalmente participa de las características de tantos de los cultivados de entonces, con afinidades y diferencias que a la larga uniformaría el uso culto común, sin la inestable "vacilación" que no entiende o exagera el análisis anacrónico. Sus autógrafos y el Quijote coinciden en el sistemático empleo de trujo, con 12 registros en el original (4) y 48 en la novela, coincidente con la anterior preferencia valdesiana frente al gusto de Correas por trajo, en años en que los textos inquisitoriales, y otros, de España y de América se atienen a una u otra forma, y los más a ambas variantes, con distintas frecuencias. El maestro Correas admite "porné o pondré" y Cervantes sigue la innovación (pondrá, tendrá), aunque recurre a la variación miradlo-miraldo con el gramático extremeño, el cual del relativo quien dice que "ia le dan i se usa otro plural quienes..., i es propio, mas no tan usado ni antiguo", registrándose un innovador quiénes en la primera parte del Quijote $(\mathrm{I}, 30)$ y tres en la segunda (II, 22, 27, 58) $)^{5}$. Esta era la propia naturalidad del español clásico, base de nuestra mejor literatura.

\footnotetext{
5 Según Gutiérrez Cuadrado en cuanto a los relativos del Quijote "lo más llamativo
} es la forma quien, invariable de acuerdo con la etimología latino-vulgar” (2015: 954), pero 
La inclinación a ver caos lingüísticos se da en algunos filólogos, impresión que respecto de los textos canarios causa leer que "la ortografía de los manuscritos es diferente no solo de uno a otro, de escribano a escribano, sino, a veces, es vacilante para cada uno. En muchos casos es difícil decidir si el escribano utilizó uno u otro signo gráfico", idea de confusión si se insiste en la dificultad que para la investigación supone "el polimorfismo gráfico", trayendo como apoyo esta inconveniente e insustancial cita ajena: "así como el hecho de que lengua hablada (= fónica) y lengua escrita (= gráfica) están en constante evolución en sus relaciones, una evolución que se da en los dos sentidos: en cada etapa evolutiva, a diferentes fonemas -unidades del nivel fonológico- corresponden diferentes grafemas - unidades del nivel grafémico-" (Samper, Cáceres, González, Monteanu, Corbella y Medina 1996: 293) . De hecho, la presunción de anarquía en la ortografía o en la lengua ha sido episódica en la filología española, desde la situación caótica que se atribuyó al romance primitivo, al supuesto caos ortográfico en la América de la independencia o a la prevención contra la variación lingüística, sobre todo si es en América, vista como una amenaza a la unidad del idioma, trayéndose al presente académico discusiones decimonónicas cuya oportunidad y sentido no hace mucho Lázaro Carreter rechazaba (1994: 20)7.

hasta entonces eso era lo de principalísima frecuencia en la lengua escrita, sobre todo en la literaria. A mi modo de ver, lo verdaderamente llamativo es el registro de cuatro quiénes entre las dos partes de la novela, pues es lo que supone un paso en la admisión por Cervantes de la innovación popular. Por supuesto, la comparación entre distintos corpus de autores cultivados, y en el seno de cada uno de ellos, ofrece más referencias sobre cómo se estaba desarrollando la competencia entre variantes, con tradición e innovación de fondo, así entre "padre y hijo" / "padre e hijo", vía / veía, vido / vio, traduzgo / traduzco, cayo / caigo, vamos / vayamos, amávades / amabais, etc. De estas y otras cuestiones normativas me he ocupado en otras partes $(2002,2015,2016)$.

6 Pero mucho más difícil de asumir es ese tipo de "constante evolución" de la cita de Carrera de la Red, estudiosa que, por cierto, en documento de 1539 dado en tierras bogotanas da meitad como "reinterpretación de una forma medieval meatad", luenga y priesa como "fluctuaciones en el vocalismo tónico"; cree que "el nombre fee duplica la vocal", que ábile, estérile, ynterese, puros latinismos, son "casos de -e paragógica", y le extraña sobremanera encontrar por entonces escuro, espital y treslado, aparte de posteriores "curiosidades" sobre el seseo, de lo que en otra parte he dado cuenta (2010: 96-98).

7 He aquí una nueva declaración académica sobre dicha cuestión, esta de Juan Luis Cebrián: "la dimensión panhispánica reclama igualmente una enorme atención, y mantener una estrecha relación con las Academias hermanas de Iberoamérica a fin de garantizar la unidad del idioma": https://www.abc.es/cultura/abci-juan-luis-cebrian-sobre-intenciones-dirigirsentiria-inmensamente-honrado-201810060113_noticia.html. Otro académico, este uruguayo, simplemente reconoce que en ningún momento la lengua española se cuestionó en América tras su independencia, y que aun con las reformas ortográficas de Bello y Sarmiento, de haber triunfado, "no se habría dañado" su presencia en tierras americanas, sin que la ruptura hubiera 


\section{LA CUESTIÓN ORTOGRÁFICA ENTRA EN JUEGO}

La desorientación que en materia ortográfica y fonética aqueja a no pocos historiadores de la literatura, y a algunos de la lengua también, ha hecho que en el aparato crítico de la edición Rico 2015 se traigan sin crítica estas palabras de 1954 de Romera Navarro:

Sin duda tendría Cervantes ciertas preferencias y hábitos fonéticos y ortográficos, pero eran tan flexibles (o laxos), que no le impedían escribir unas veces tuue y otras tube, o bien e y he (de haber), ansí, assí y así, rescibos, reçiuo, receuí y reciuí, mesmo y mismo, dozientas, duzientas y docientas, etc., etc. (VC 785).

Pareciera que esto solo le hubiera ocurrido al genio de Alcalá, o que entonces ansí en una u otra medida no lo empleara cualquier culto, por cierto que en el Quijote se cuentan 1.065 asi por 62 ansí, y en cuanto a la variación assi-así, sería cosa de la imprenta, pues en sus autógrafos exclusivamente se sirvió de la $-s$ - intervocálica. Para los años en que Romera Navarro escribió el citado pasaje no extraña demasiado su indiferencia, o desconocimiento, ante lo que fonéticamente pudieron suponer los intercambios de $b$ y $u, c$ y $z$, ss y $s$, pero ya sorprende más que Rico en la justificación de sus criterios editoriales se refiera a "la modernización de la antigua serie de oposiciones entre $b$ y $v(\mathrm{o} u), s$ y $s S, c$ o ç y $z, g$ o $j$ (o $i)$ y $x$, en crisis ya a principios del siglo XVII ( VC 787), situándose fuera de la realidad fonético-fonológica del español de la época, con llamativa desinformación sobre este aspecto de la lengua de Cervantes, fundamental para comprender lo que fue su ortografía y su pronunciación ${ }^{8}$. Y posteriormente este estudioso, sobre la machacona suposición de que "Cervantes escribe continuamente desde la oralidad" y

sido posible, y centra el "problema" en la estandarización policéntrica, cuyo protagonismo en su opinión corresponde a las academias de la lengua y al Instituto Cervantes (Elizaincín 2016: 354-360), y esto, por cierto, no sin controversia ideológica.

8 Este asombroso desinterés lingüístico, tocado de desinformación, no es exclusivo de la edición Rico, pues se verifica en otras de los siglos XVI-XVII, y recientemente Gómez Canseco en la del Apócrifo dice que "el sistema fonológico antiguo se ha reducido a sus grafías correspondientes en la actualidad, resolviendo con criterios modernos las oposiciones consonánticas $b / v(\mathrm{o} u), s / s s \ldots$.. (2014: 120). Respecto de $b / v$ observa Gil que "en la época de Cervantes los dos sonidos ya no se distinguían en la mayor parte de la España castellanohablante, sobre todo en el Norte" (2015: 126), pero es muy anterior esta simplificación fonológica. 
de que el Quijote "no es un discurso escrito, sino que es, básicamente, un discurso oral" ("el Quijote es un libro para oír"), enfatiza:

Cervantes utiliza varias formas y cambia continuamente de grafía. Cervantes no tenía ni idea de ortografía, porque por entonces no existía. Los editores tenían unas reglas, pero el escritor normal y las personas corrientes no tenían ortografía: podían escribir 'haber' con 'h' o sin 'h', con ' $\mathrm{v}$ ' o con 'b', como quisiesen'.

Así que en ese "discurso oral Cervantes no vuelve atrás para corregirse", sus autógrafos difieren de este aserto, de modo que al lector moderno "no se le puede hacer entrar en este caos" ${ }^{10}$. Pero esa "crisis" del consonantismo medieval no era de "principios del siglo XVII", sino que había tenido lugar mucho antes, $y$ en sus originales se confirma plenamente el reajuste fonéticofonológico con el exclusivo empleo de la -s- (así, comisión, ayudase, diese, pagase, supiese, etc.), las alternancias conduzió-condució, hauian-abré, bizcochero-vizcocho, recibiré-receuido, y nobienbre, "cebada de leba", etc. Precisamente el que anteriormente se hubieran simplificado varios pares fonemáticos, pero manteniéndose sus viejas grafías, es lo que explica estas variaciones durante mucho tiempo, sin que fueran desconocidas de la imprenta, que no fue uniforme en sus "reglas", ni estas de estricta lógica fonético-ortográfica: de hecho, la recién fundada Academia aceptó una sumamente desfasada doble ese entre vocales, incluso la serpentina alta de la que había abominado Mateo Alemán. Claro que se habían publicado varias ortografías desde la nebrisense, y en gramáticas como la de Antonio del Corro; pero la enseñanza se regía por cánones muy distintos a los que mucho más tarde se impondrían. De hecho, si el editor hubiera tenido en cuenta la lengua de los autógrafos, en ellos habría encontrado una palpable muestra de alteración en la imprenta del original de la novela cervantina, ya que en el Quijote es normal la anticuada ss, etimológica o no: assí, assentó, desseo, passaua, pudiesse, sacasse, etc.

No se está "en un momento en que la ortografía empieza a regularizarse" (Gutiérrez Cuadrado 2015: 948, 950). El castellano medieval la tenía bastante

\footnotetext{
9 https://cronicaglobal.elespanol.com/letra-global/la-charla/francisco-rico_132824_102. html

10 Ibíd. En sus originales regularmente pone cunpla, cunplir, cumplimiento $(3,6)$, y corrige compliré en cumpliré (7), en sintonía con la regularidad que al respecto habrá en el Quijote; en ellos hay un Çervantes sobre Cervantes y un Iingenio con la minúscula $i$ tachada (12), Malaga enmendando a Malaha (11), y el inquietante retoque de sertificación en certificación (6), sin contar con un saqó rectificado sacó (5).
} 
regularizada en muchos amanuenses hasta que se iniciaron los cambios consonánticos, aunque de ese pasado también le llega a Cervantes su grafía Enrrique (9), el empleo de $n$ ante $b$ y $p$, o su enmendado saqó, y el humanismo latinizante haría que el secretario real Juan de Coloma repetidamente corrigiera cotidiana por quotidiana (Frago 2018: 241), como Cervantes alternó cuenta-quenta (5) y (11) ${ }^{11}$. De modo que, una vez rotos los anteriores nexos fónicos, etimologizantemente se restituirían caballo, escribir, hombre, vivir, volver o haber y la $-b$ - del imperfecto de indicativo latino amabam; pero estas innovaciones tardarían en generalizarse, coexistiendo largamente el medieval auía con la innovación habia, o habré con auré, hauré y abré; otras se desecharían, p. ej. illustre del autógrafo (1), sin que hubiera caos ni incomprensión alguna en esa lengua escrita, que era de la mayoría. Quienes de estas cuestiones tratan tal vez se sorprenderán de cómo manuscribían sus cartas a finales del siglo XVIII y principios del XIX no "personas corrientes", sino individuos encumbrados social y económicamente, en España, por ejemplo hombres de negocios gaditanos o el mismo Goya, y en América, también en lo que a la puntuación ortográfica concierne.

\section{ENMIENDAS DISCUTIBLES Y UNA MUY IMPROPIA}

Una indebida corrección al Quijote en la edición Rico 2015 es la concerniente al pasaje "aunque por conjeturas verisímiles se deja entender que se llamaba Quijana" (I, 1, p. 39), en la príncipe "aunque por conjeturas verosímiles se dexa entender que se llamaua Quexana" ${ }^{2}$, porque "salvo aquí, los textos cervantinos traen siempre las formas con veri-" (VC, 804). En el corpus quijotesco efectivamente lo demás es "trazas verisímiles" (I, 48, p. 606),

11 Una grafía medieval como la de rrazón y onrra con mucha profusión se halla en el siglo XVII y dura hasta el XIX, con ocasionales dobletes como contador-qontador, acá-aquá o que-qe, y un caso como el americano saceado ‘saqueado' escrito en La Paz el año 1809 por un cura originario de Tucumán: BNE, ms. 13.150. Incluso no faltan testimonios literarios como cue 'que' en Juan del Encina, abarce 'abarque' y ascear 'asquear' en autógrafo de Gracián, arrancen 'arranquen' en Mateo Alemán, o un qasquibano en códice de la Biblioteca Colombina, enmendado casquibano como el saqó de Cervantes (Frago 2002: 126-163). Pero estas eran grafías sueltas, que no empañaban la comprensión textual, en tanto que la $r r$ de Enrrique del alcalaíno fue de uso frecuentísimo en los manuscritos de su época, y posteriores, de autores que no podrían tacharse de incultos.

$12 \mathrm{http} / / / \mathrm{bdh}-$ rd.bne.es/viewer.vm?id=0000042946 
"contingibles y verisímiles" (II, 24, p. 905), "son falsas, y parte verisímiles" (II, 25, p. 922), además de verisimilitud (I, 48, p. 600). Ahora bien, el criterio cuantitativo en rigor debería aplicarse a similares casos de variantes y, sobre todo, se está gratuitamente uniformando la lengua de Cervantes, mientras el CORDE entre 1600 y 1620 recoge 78 verisímil por 28 verosímil, con la particularidad de que el corpus académico aquí se basa en la edición Rico y no en la príncipe, quitando, pues, un caso de innovación al texto cervantino $\mathrm{y}$ al conocimiento del español de la época ${ }^{13}$. Por cierto, Rico en la primera cita asimismo sustituye Quexana de la príncipe por Quijana, por ser "apellido irreal", aventurando que "los contemporáneos la veían como una errata obvia, probablemente atraída por el dexa contiguo" $(V C, 804)$, aunque Quejana es conocido nombre de familia, así entre pasajeros a Indias.

Si esas libertades editoriales son muy discutibles, del todo arbitraria y de contrariedad lingüística es la que sigue, en relación con los verbos transitivos ensillar y enalbardar, que asimismo podían construirse con su complemento elíptico. Con total corrección $(\mathrm{V}+\mathrm{CD})$ y respeto a la princeps se da el pasaje que presenta a Sancho cuando aún estaba "tan molido y quebrantado" por la ingesta del bálsamo de Fierabrás:

Pero don Quijote, que, como se ha dicho, se sintió aliviado y sano, quiso partirse luego a buscar aventuras, pareciéndole que todo el tiempo que allí se tardaba era quitárselo al mundo y a los en él menesterosos de su favor y amparo,y más, con la seguridad y confianza que llevaba en su bálsamo. Y así, forzado de este deseo, él mismo ensilló a Rocinante y enalbardó al jumento de su escudero, a quien también ayudó a vestir y a subir en el asno. Púsose luego a caballo... (I, 17, p. 198).

13 Este corpus electrónico todavía en la entrada ancheta, término comercial de muy tardía aparición, incluye un diminutivo del adjetivo ancho ("ancheta de caderas") del Arcipreste de Hita, y aún refiere batea, indigenismo antillano que no arabismo, a la prosa alfonsí, donde lo que se lee es batéase 'bautízase'. REALACADEMIA ESPAÑOLA: Banco de datos (CORDE) [en línea]. Corpus diacrónico del español. <http://www.rae.es $>$ [28/08/2019]. En varias ocasiones, y desde hace muchos años, con debida argumentación había advertido sobre el hecho de que en el diccionario académico se mantuvieran contumazmente errores tan llamativos como el de un bizarrón 'candelabro grande' supuestamente derivado de bizarro, siendo un mero apellido vasconavarro, un azoche, por el antiguo aragonesismo azoque, simple medievalismo gráfico (ch de /k/) y pollo 'caballón', caso absurdo en la entrada en que aparecía, despropósitos lexicográficos que solo se eliminaron en la edición de 2014 (DLE), a pesar de lo que en 2003 me escribía el recordado Lázaro Carreter: "Sus observaciones al $D R A E$ serán muy tenidas en cuenta. Y el saber que su revisión de aragonesismos no se había incorporado a la última edición me tranquiliza: cuantas observaciones hacía yo a propósito de ellos se estimaban con sospecha, con el argumento de que ya los había revisado usted". 
Este vivo cuadro con rotundos y precisos trazos pinta el ansia de don Quijote por marchar a sus andanzas caballerescas, apremio refrendado por el reiterado luego de inmediatez, por la secuencia oracional dependiente de pareciéndole y por las inusitadas acciones del caballero, propias del escudero. Pero el desafuero viene en anterior escena de parecido esquema narrativo, también con luego repetido, cuando los pastores despiertan a don Quijote, preguntándole "si estaba todavía con propósito de ir a ver el famoso entierro de Grisóstomo", y él, "que otra cosa no deseaba, se levantó y mandó a Sancho que ensillase y enalbardase al jumento, lo cual él hizo con mucha diligencia, y con la mesma se pusieron luego todos en camino" (I, 13, p. 148); esto,obviamente,en la edición Rico 2015, porque en la príncipe lo que se lee es "y enalbardase al momento". Este cervantista por su cuenta rompe el esquema gramatical del texto cervantino, pues ya no van los dos verbos con complemento implícito, como en otros sitios de la novela también se hallan, sino que se lo pone solo al segundo ("y enalbardase al jumento"), en sustitución de la locución al momento, eliminando así el complemento adverbial de los coordinados ensillar y enalbardar.

Tal vez cabría traer aquí la expresión "toda exégesis eludo" frecuente en don Manuel Alvar para casos no tan chocantes como este, en el que falla el explícito compromiso editorial de explicar las notas. En este caso más tarde se aclararía la repentina "intuición" de Rico, con entusiasmo escatológico realzada en entrevista periodística: "En un determinado momento, Don Quijote y Sancho van a salir y dice el texto que Sancho ensilló a Rocinante y 'enalbardó al momento'. Una mierda al momento: es al jumento". Y el periodista: "Vibra aún el filólogo Francisco Rico... ante su enésimo hallazgo en el Quijote"14.

\section{REFERENCIAS BIBLIOGRÁFICAS}

Autógrafos. 2015. Autógrafos de Miguel de Cervantes Saavedra. Edición facsímil y estudios. Madrid: Taberna Libraria.

14 https://elpais.com/ccaa/2016/01/08/catalunya/1452286758_615849.html. Arturo Pérez Reverte en "Paco Rico, autor del Quijote", artículo de contestación a otro del cervantista, "de confusa sintaxis y ortografía y con mala cita latina", puntualiza: "Unos publicamos novelas con más o menos fortuna y otros manosean Quijotes. Pero en el caso de Paco Rico, en mi opinión, eso ha terminado por hacerle creer que posee una especie de derecho exclusivo, o de propiedad intelectual, sobre las palabras Cervantes y Quijote": El País, 18-10-2016, p. 29. 
Cervantes, Miguel De. 2015. Don Quijote de la Mancha. Francisco Rico (ed.). Madrid: Real Academia Española.

Corominas, Joan y José A. Pascual. 1980-1991. Diccionario crítico etimológico castellano e hispánico. Madrid: Editorial Gredos.

Covarrubias, Sebastián De. 1611/1984. Tesoro de la lengua castellana o española. MadridMéxico: Ediciones Turner.

ElizAincín, Adolfo. 2016. La mirada americana: el español y su expansión internacional. $E l$ español en el mundo. Anuario del Instituto Cervantes 2016. Madrid: Instituto Cervantes, pp. 333-365.

Fernández Gómez, Carlos. 1962. Vocabulario de Cervantes. Madrid: Real Academia Española.

Frago, Juan Antonio. 2002. Textos y normas. Comentarios lingüisticos. Madrid: Editorial Gredos.

2010. Letras, sonidos y contextos sociolingüísticos en la historia del español. En Sara Gómez Seibane y José Luis Ramírez Luengo (eds.). Maestra de muchos. Estudios filológicos en homenaje a Carmen Isasi Martínez, pp. 93-100. Buenos Aires: Ediciones Voces del Sur.

2015. Don Quijote. Lengua y Sociedad. Madrid: Arco Libros.

2016. El Quijote. Lengua y proyección americana: http://congresosdelalengua.es/ puertorico/mesas/frago-juanantonio.htm

2018. La lengua del testamento de Juan de Coloma. Entre el medievalismo y el humanismo renacentista. Cuadernos de Estudios Borjanos 61: 219-250.

Gil, Juan. 2015. La ortografía de Cervantes. Autógrafos de Miguel de Cervantes Saavedra. Madrid: Taberna Libraria, pp. 115-169.

Gómez Canseco, Luis (ed.). 2014. "Alonso Fernández de Avellaneda". El ingenioso hidalgo don Quijote de la Mancha. Madrid: Real Academia Española.

Gutiérrez Cuadrado, Juan. 2015. La lengua del Quijote: rasgos generales. En Francisco Rico (ed.). Don Quijote de la Mancha, pp. 947-986. Madrid: Real Academia Española.

LÁzaro Carreter, Fernando. 1994. La Real Academia y la unidad del idioma. Actas del Congreso de la Lengua Española. Sevilla, 1992. Madrid: Instituto Cervantes, pp. 7-21.

Nebrija, Antonio De. 1492/1981. Gramática de la lengua castellana. Antonio Quilis (ed.). Madrid: Editora Nacional.

Samper Padilla, José Antonio, Ma Teresa Cáceres Lorenzo, Rosa Ma González Monllor, Dan Munteanu, Dolores Corbella y Javier Medina López. 1996. El estudio histórico del español de Canarias. En Javier Medina López y Dolores Corbella Díaz (eds.). El español de Canarias hoy: análisis y perspectivas, pp. 285-303. Madrid: Iberoamericana. 